\title{
In Vivo hepatoprotective and antidiabetic activities of essential oils from Boenninghausenia albiflora (Hook.) reichb. ex heynkh, of Pakistan
}

\begin{abstract}
In the present work essential oils extracted from different parts of a medicinally important shrub, Boenninghausenia albiflora, were evaluated for their hepatoprotective effect and hypoglycaemic activity. GC/MS analysis indicated that monoterpenes, sesquiterpenes, ketones, esters and alcohols dominated in all essential oils. The hepatoprotective potential of essential oils was studied in vivo in Wistar albino rats against carbon tetrachloride induced hepatotoxicity. The hepatoprotective activity was determined on the basis of their effects on biomarkers like aspartate aminotransferase (AST), alanine aminotransferase (ALT), lactate dehydrogenase (LDH), alkaline phosphatase (ALP), bilirubin and total protein (TP). All essential oils exhibited hepatoprotective activity in comparison with the standard drug. For antidiabetic activity two doses of essential oils i.e. 50 and $200 \mu \mathrm{L} / \mathrm{Kg}$ body weight were introduced into alloxan induced diabetic rabbits. Although both doses were found effective to have hypoglycaemic effect but higher dose showed better control over diabetes, comparable to that of Glib (positive control). It can be concluded from the results that these essential oils can play significant role not only in the liver protection but also in management of diabetes.
\end{abstract}

Volume 4 Issue I - 2017

\author{
Ferhat Mehmood,' Phool Shahzadi, ${ }^{2}$ Zaheer- \\ Ud-Din Khan,' Najma Arshad, ${ }^{3}$ Muhammad \\ Bilal, ${ }^{4}$ Zahida Perveen, ${ }^{5}$ Muhammad Rizwan ${ }^{6}$ \\ 'Department of Botany, GC University, Pakistan \\ 'Glass and Ceramics Research Center, Pakistan \\ ${ }^{3}$ Department of Zoology, University of the Punjab, Pakistan \\ ${ }^{4}$ Applied Chemistry Research Center, Pakistan \\ ${ }^{5}$ Department of Statistics and Computer Sciences, University of \\ Veterinary and Animal Sciences, Pakistan \\ ${ }^{6}$ Govt. College Township Lahore, Pakistan
}

\begin{abstract}
Correspondence: Phool Shahzadi, Glass and Ceramics Research Center, PCSIR, Labs. Complex Lahore, Pakistan, Email psk_a@yahoo.com
\end{abstract}

Received: June 17, 2017 | Published: October 25, 2017

Keywords: boenninghausenia albiflora, essential oil, hepatoprotective activity, hypoglycaemic effect, monoterpenes, sesquiterpenes, alcohols

Abbreviations: AST, aspartate aminotransferase; ALT, alanine aminotransferase; LDH, lactate dehydrogenase; ALP, alkaline phosphatase; TP, bilirubin and total protein; HED, human equivalent dose; SGPT, glutamic pyruvic transaminase; SGOT, glutamic oxaloacetic transaminas

\section{Introduction}

Although there are many plant families in Pakistan including essential oil rich plants, but Rutaceae represented by 11 genera and 27 species, many of which have been naturalized here being cultivated and hybridized for edible, medicinal and ornamental purposes. Many genera especially wild plants with essential oils and commercially viable new hybrid still need to be analyzed thoroughly regarding their ethnopharmacological significance. Boenninghausenia albiflora is a monotypic genus found in temperate Himalayas. Commonly found in the N. of Pakistan (Hazara and Murree Hills) at 200-3000m, growing in shady forest. The plant has an unpleasant smell and the roots have a spicy fragrance. Locally called "Pissu. Mar" or flea killer, its leaves when crushed emit a strong foetid smell and used as a flea powder. As a result of indiscriminate use of antimicrobial drugs in the treatment of infectious diseases, microorganisms have developed resistance to many antibiotics. ${ }^{1}$ There is a need to develop alternative antimicrobial drugs. One approach is to screen local medicinal plants, which represent a rich source of novel antimicrobial agents. Boenninghausenia albiflora belonging to the family Rutaceae and is well known for its medicinal properties in traditional system of medicine. In ethnobotanical literature, the aerial as well as the root part has been described as an antiseptic while leaf part has been used to apply on cuts and wounds whereas root powder is being used as antiseptic. ${ }^{2}$ Some-times its juice is also being given in vomiting and dysentery, while some workers also reported this plant to have flea repellent, ${ }^{3}$ as well as calcium blocking activity. ${ }^{4}$ The present study was carried out to investigate the chemical composition of its essential oils, antioxidant potential and the antimicrobial properties. As no previous records on these aspects of this plant could be found in the literature in Pakistan, the present study claims some useful results.

\section{Experimental}

Plant material was obtained from its natural habitat, identified and authenticated by a botanist in Dr. Sultan herbarium, GC University, Lahore. The respective plant parts were separated and subjected to hydro-distillation for about four hours. The essential oils obtained thus were dried over anhydrous sodium sulphate and stored in dark colored glass bottle at temperature of about $4^{\circ} \mathrm{C}$.

\section{GC-MS analysis of essential oils}

GC-MS analyses were performed using a Shimadzu GCMSQP2010A system in EI mode $(70 \mathrm{eV})$ equipped with an injector at $250^{\circ} \mathrm{C}$ and a DB-5MS column. Samples were injected at $250^{\circ} \mathrm{C}$ with a split ratio of 50/50. Injection volume was $1 \mu 1$ and electronic pressure programming was used to maintain a constant flow $(0.67 \mathrm{ml} / \mathrm{min})$ of the helium as carrier gas. The oven temperature was programmed from $100^{\circ} \mathrm{C}(4 \mathrm{~min})$ to $250^{\circ} \mathrm{C}$ at a rate of $2^{\circ} \mathrm{C} / \mathrm{min}$ and held at this temperature for $2 \mathrm{~min}$. The mass spectrometer was set to scan the mass range $40 \mathrm{amu}$ to $600 \mathrm{amu}$ with ion source temperature $200^{\circ} \mathrm{C}$ and interface temperature $250^{\circ} \mathrm{C}$. Analyses were performed in triplicate with a blank run after every analysis. The resulting data was processed using Shimadzu Lab Solution GCMS Post-run Analysis software. The relative apparent percentage of each compound and of their classes was determined by area normalization method. Identification of 
compounds was made by comparing with the mass fragmentation pattern of the reported data in NIST 147 and NIST 27 libraries.

\section{Determination of hepatoprotective activity}

Preparation of animal house for rats and feeding routine: Male Wistar albino rats, Rattus norvegicus with weight $250 \pm 20 \mathrm{~g}$, taken from the Animal House, University of Veterinary and Animal sciences, Lahore, were held in standard cages placed in the animal house at Zoology Dept., University of the Punjab, Quaid-i-Azam Campus, Lahore, for 7 days for acclimatisation. Standard pellet diet and tap water were supplied ad libitum.

Liver toxicity induction: Liver toxicity was induced by $\mathrm{CCl}_{4}$. It's toxicity has been characterized extensively and a link is recognised between its metabolism, generation of free radicals, and peroxidative decomposition of cytoplasmic membrane structural lipids. ${ }^{4}$ Additionally, $\mathrm{CCl}_{4}$-induced toxicity causes centrilobular necrosis and leakage of cellular enzymes into blood stream.

Solvents used as dilutors: Tween 20 was used as dilutor for the essential oils of the plant parts under study.

Grouping of animals: After acclimatization for 7 days all rats were distributed into 6 groups (A, B, C, D, E and F of five rats each. Group $\mathrm{A}$ acted as untreated uncompromised, control and was not given any treatment. Group B also treated as control was given was administered with $50 \mu 1$ of Tween 20 dissolved in equal amount of water. Each groups viz. $\mathrm{C}, \mathrm{D}$ and $\mathrm{E}$ of rats received single dose of essential oil, i.e. $50 \mu \mathrm{L}$, that corresponds to the human equivalent dose (HED) as per following formula: $\mathrm{HED}=$ rat dose $/ \mathrm{kg}$ (weight of rat in $\mathrm{kg} /$ weight of human in $\mathrm{kg}$ ) 0.33 , dissolved in $50 \mu \mathrm{l}$ of Tween 20 by stainless feeding needle for fourteen days. Group R acted as positive control group. This group was administered with locally available drug, Silymarin. This drug was used @ $100 \mathrm{mg} / \mathrm{kg}$ diluted in Tween 20 also.

Collection of blood: Four hour after the last dose, a single dose of $\mathrm{CCl}_{4}(1.5 \mathrm{mg} / \mathrm{kg}$ in ratio of $1: 1$ olive oil $\mathrm{v} / \mathrm{v})$ was administered orally to animals of all the groups except controls (groups A and B). After $24 \mathrm{~h}$, blood sample of each of the animals was obtained from the heart in a centrifuge tube. The blood samples were allowed to coagulate for $30 \mathrm{~min}$ at $37^{\circ} \mathrm{C}$ and then serum was separated by centrifugation at $2500 \mathrm{rpm}$ at $10^{\circ} \mathrm{C}$ for $10 \mathrm{~min}$ that was stored at $-80^{\circ} \mathrm{C}$ until analyzed. A portion of liver of each of the animals was preserved in neutral buffered formalin (10\%) for histology.

Biochemical analysis for determination of liver function biomarkers: The serum samples were analyzed for the determination of aspartate aminotransferase (AST), alanine aminotransferase (ALT), lactate dehydrogenase (LDH), alkaline phosphatase (ALP), bilirubin and total protein (TP). The analysis was carried out in Biochemistry Laboratory of Mayo Hospital Lahore using RIELE Semi Automated Chemistry Analyser, Photometer 5010 $\mathrm{V}_{5}+$, Robert Riele Gmbh \& Co KG (Germany) Software version 5.1, Documentation Version 1.2008.

Assessment of liver toxicity: To assess hepatic toxicity, serum samples of each of the animals of group A to F were subjected to biochemical analysis for the estimation of liver function markers and the results were compared between these groups.

\section{Evaluation of antidiabetic activity}

Preparation of animal house for rabbits: Rabbits Oryctolagus cuniculus weighing $>750 \mathrm{~g} \pm 20$ and aged $8-12$ months were kept in the animal house earthen pots were kept in animal house for rabbits. Ani- mal house was twenty feet in length, ten feet in width. Standard conditions were maintained in the animal house regarding its temperature, relative humidity along with dark and light cycle.

Preparation of alloxan diabetic rabbits: The rabbits were made diabetic by injecting intravenously alloxan monohydrate $150 \mathrm{mg} / \mathrm{Kg}$ body weight. This dose permanently destroys the beta cells of pancreas and produces diabetes mellitus. Eight days after injection of the alloxan monohydrate, blood glucose of all the surviving rabbits was determined by checking direct glucose level by glucometer. Water and diet were available to the animals throughout the treatment period. After eight days rabbits confirmed diabetic with blood glucose level from $200-500 \mathrm{mg} / 100 \mathrm{ml}$ were selected for the evaluation for antidiabetic activity.

Experimental plan: After acclimatization for 7 days all rabbits were distributed into 5 groups (A, B, C, D, E, F, G and $\mathrm{H}$ of five rabbits each. The group $\mathrm{A}$ acted as control and was not given any treatment, but $10 \mathrm{ml}$ water. The group $\mathrm{B}$ and $\mathrm{C}$ received an application of 50 and $200 \mu \mathrm{L} / \mathrm{kg}$ body weight, of EO from leaves $B$. albiflora diluted in $\mathrm{CMC} 1 \%$ and water. The group $\mathrm{D}$ and $\mathrm{E}$ received an application of 50 and $200 \mu \mathrm{L} / \mathrm{kg}$ body weight, of EO from stem of B. albiflora diluted in $\mathrm{CMC} 1 \%$ and water. The group $\mathrm{F}$ and $\mathrm{G}$ received an application of 50 and $200 \mu \mathrm{L} / \mathrm{kg}$ body weight, of EO from root of B. albiflora diluted in $\mathrm{CMC} 1 \%$ and water. Group $\mathrm{H}$ acts as positive control group. This group was administered with locally available drug, Glibenclamide (Glib.). This drug was used in $0.5 \mathrm{mg} / \mathrm{ml}$ in concentration diluted also in $10 \mathrm{ml}$ of $1 \% \mathrm{CMC}$. The glucose level was recorded after 5, 10, and 24 hours daily.

Acute oral toxicity: Acute oral toxicity of all essential oils was carried out adopting "up and down procedure" as per given in the OECD guidelines, Anonymous. ${ }^{5}$ Four groups each of rabbits and rats were formed separately, having 5 animals each. Weights of overnight fasting animals were taken and an oral dose of each essential oil @ $2000 \mathrm{mg} / \mathrm{kg}$ was given to one animal of each of the groups. Food was stopped for further $3 \mathrm{hrs}$ and the animals were observed, once during the first $30 \mathrm{~min}$ and then for $24 \mathrm{~h}$ at regular intervals with special attention in the first $4 \mathrm{~h}$. All animals survived; the same dose was given to the additional 4 animals of each group, and observations were made for 14 days as per OECD guidelines.

Statistical analysis: One-way ANOVA and Probit-Regression tests were applied, using SPSS 13.0 (statistical soft ware) on the data for statistical analysis to draw conclusions.

\section{Results and discussion}

\section{Hypoglaecimic effect}

STZ-induced $\beta$-cell death in the pancreas is due to the alkylation of DNA, hence producing hyperglycaemia, Elsner et al. ${ }^{6}$ Both low and high concentrations of essential oils have exhibited hypoglaecemic effect. Immediate drop in the blood glucose levels can be seen. Effect of high dose of essential oil is about almost equal to the low dose. However results of both doses i.e. 50 and $200 \mu \mathrm{L} / \mathrm{kg}$ of essential oils (Table 1) are far better than the effect of Glib (positive control) Figure 1. All these findings suggest that essential oils may be acting through some mechanism to improve the receptor-responsiveness to insulin causing increased sugar uptake by the tissue. It is very difficult to comment on the exact mechanism of hypoglycaemic activity of essential oils, since the study was not designed accordingly. However $\mu$-linalool and alcohols present in B. albiflora essential oils could 
be responsible for its hypoglyceamic activity by virtue of their antioxidant property, Rajanarayana et al. ${ }^{?}$

\section{Hepatoprotective effect}

The formation of free radicals in $\mathrm{CCl}_{4}$-induced liver stress results in a sharp increase in lipid peroxidation, which is not localized, hence, propagates between the cells to interact with phospholipids causing structural destructions. ${ }^{8}$ This destruction results in a loss of functional integrity of cell membrane, which causes the leakage of certain biomarkers into blood stream. These biomarkers, ALT, AST, ALP, LDH and bilirubin, are extensively being used to assess the liver function. ALT is also called serum glutamic pyruvic transaminase (SGPT) and is found in liver, kidney, heart and muscles. The content of this important biomarker is raised into blood stream in hepatic injury/toxicity because it leaks out from hepatocytes. Another marker, AST, also known as serum glutamic oxaloacetic transaminase (SGOT), is found in liver parenchyma cells, erythrocytes, cardiac tissue and skeletal muscles. In conditions involving hepatic disorders, level of AST is raised into blood stream. ALP is found in cell linings of biliary tract, the bones and placenta, and in liver damage or biliary obstruction, it enters into blood stream. LDH is another important enzyme responsible for inter conversion of pyruvate and lactate, and in oxidative stress its level is raised in blood. The level of these biomarkers in oils treated groups indicates that hepatocytes have shown resistance against free radicals of $\mathrm{CCl}_{4}$. Essential oils have shown hepatoprotectibe activity. ${ }^{9-14}$ In the present study, all essential oils have helped hepatocytes to resist against free radicals of $\mathrm{CCl}_{4}$, Table 2, indicates the effect of hepatotoxicity induced by $\mathrm{CCl}_{4}$. Figure 2 gives a picture of percent reduction in the raised values of biochemical markers. According to this maximum reduction in ALT was done by essential oil from roots and leaves followed by essential oil from stem. Maximum reduction in AST was done by essential oil from stem followed by leaves and roots Max reduction in Alkaline Phosphatases was by essential oil from root followed by oils from stem and leaves. As far as reduction in Bilirubin was concerned maximum reduction was shown by essential oil from roots and leaves followed by stem. Similarly reduction in total proteins was done by essential oil from root and stem that was upto $9.8 \%$ followed by $8.19 \%$ by essential oil from leaves. Maximum reduction in LDH value was done by essential oil from $B$. albiflora leaves followed by stem and roots. The essential oils not only offered protection but also caused start of regenerative process, which is a very encouraging effect in this regard. The essential oils have high content of flavonoids, alcohols and terpenes, which have contributed in hepatoprotective activity of the extracts through enhancing antioxidant mechanism of the animals. This claim is supported by Vimala et al. ${ }^{15}$ The administration of all essential oils for 14 days have protected the hepatocytes against $\mathrm{CCl}_{4}$-induced toxicity. Hence, the use of these essential oils as food supplement may be helpful to protect liver from oxidative damage in hepatitis and diseases involving long-term therapy.

Table I Effect of different doses of different EOs on oral glucose tolerance in alloxan treated rabbits $(n=5)$

\begin{tabular}{|c|c|c|c|c|}
\hline \multirow[t]{2}{*}{ Treatments } & \multirow[t]{2}{*}{ Glucose level alloxan induced rabbits $\mathrm{mg} / \mathrm{dl}$} & \multicolumn{3}{|c|}{ Glucose level mg/dl (Mean \pm SEM) } \\
\hline & & $5 \mathrm{hrs}$ & IOhrs & $24 \mathrm{hrs}$ \\
\hline \multicolumn{5}{|l|}{ EO $50 \mathrm{~mL} / \mathrm{kg}$} \\
\hline B. albiflora Leaves & $225 \pm 0.98$ & $214 \pm 1.30$ & $143.6 \pm 1.07$ & $120.6 \pm 0.67$ \\
\hline B. albiflora Root & $230 \pm 0.23$ & $217.5 \pm 1.15$ & $151.2 \pm 0.58$ & $119.2 \pm 0.86$ \\
\hline B. albiflora Stem & $229 \pm 0.41$ & $216 \pm 1.33$ & $147 \pm 0.70$ & $123 \pm 0.68$ \\
\hline \multicolumn{5}{|l|}{$\mathrm{EO} 200 \mathrm{~mL} / \mathrm{kg}$} \\
\hline B. albiflora Leaves & $230 \pm 0.40$ & $211 \pm 0.70$ & $135.2 \pm 0.86$ & $118.2 \pm 1.24$ \\
\hline B. albiflora Root & $22 I \pm 0.62$ & $200.8 \pm 0.86$ & $|40.4 \pm 0.8|$ & $110.8 \pm 0.86$ \\
\hline B. albiflora Stem & $225 \pm 0.92$ & $214.6 \pm 0.59$ & $|52.6 \pm 0.8|$ & $129 \pm 1.24$ \\
\hline Glib $0.5 \mathrm{mg} / \mathrm{ml}$ & $342 \pm 0.58$ & $137 \pm 0.70$ & $131.6 \pm 0.50$ & $111.6 \pm 0.50$ \\
\hline Water & $222 \pm 0.33$ & $225.6 \pm 0.50$ & $233.6 \pm 0.50$ & $242.4 \pm 0.92$ \\
\hline
\end{tabular}

*Values expressed as means \pm SEM.

Table 2 Biochemical analyses to show the effect of essential oils on $\mathrm{CCl} 4$ induced hepatotoxicity in rats $(n=5)$

\begin{tabular}{lllllll}
\hline Treatment & ALT IU/L & AST IU/L & $\begin{array}{l}\text { Alkaline } \\
\text { phosphatases } \\
\text { IU/L }\end{array}$ & $\begin{array}{l}\text { Bilirubin } \\
\text { (direct) } \\
\text { mg/dl }\end{array}$ & $\begin{array}{l}\text { Total } \\
\text { protien g/dl }\end{array}$ & $\begin{array}{l}\text { Lactate } \\
\text { dehydrogenase } \\
\text { IU/L }\end{array}$ \\
\hline Control & $33.33 \pm 6.00$ & $111.64 \pm 3.17$ & $385 \pm 3.24$ & $0.36 \pm 0.03$ & $5.66 \pm 0.12$ & $2039.33 \pm 3.11$ \\
Control(Tween 20) & $49.33 \pm 0.66$ & $190 \pm 3.00$ & $349 \pm 5.76$ & $0.53 \pm 0.03$ & $5.8 \pm 0.17$ & $2095 \pm 2.10$ \\
$\begin{array}{l}\text { CCl Induced } \\
\text { Boenninghausenia albiflora }\end{array}$ & $183.33 \pm 1.68$ & $272.66 \pm 3.89$ & $519.66 \pm 0.18$ & $0.5 \pm 0.03$ & $6.1 \pm 0.31$ & $4248 \pm 4.84$ \\
Roots & $23.33 \pm 1.20$ & $174.33 \pm 3.84$ & $268.33 \pm 2.02$ & $0.36 \pm 0.03$ & $5.5 \pm 0.05$ & $2468.33 \pm 1.69$ \\
B. albiflora Stem & $46.66 \pm 0.88$ & $141 \pm 5.5$ & $344 \pm 1.93$ & $0.4 \pm 0.00$ & $5.5 \pm 0.08$ & $2315.33 \pm 1.98$ \\
B. albiflora Leaves & $29.66 \pm 0.88$ & $167.66 \pm 4.3$ & $386.33 \pm 1.78$ & $0.36 \pm 0.03$ & $5.6 \pm 0.11$ & $2042.66 \pm 4.60$ \\
Control (Silymarin) & $40 \pm 5.00$ & $185.66 \pm 1.75$ & $344 \pm 1.87$ & $0.4 \pm 0.05$ & $5.3 \pm 0.03$ & $1710 \pm 2.22$ \\
\hline
\end{tabular}

*Values expressed as means \pm SEM. 


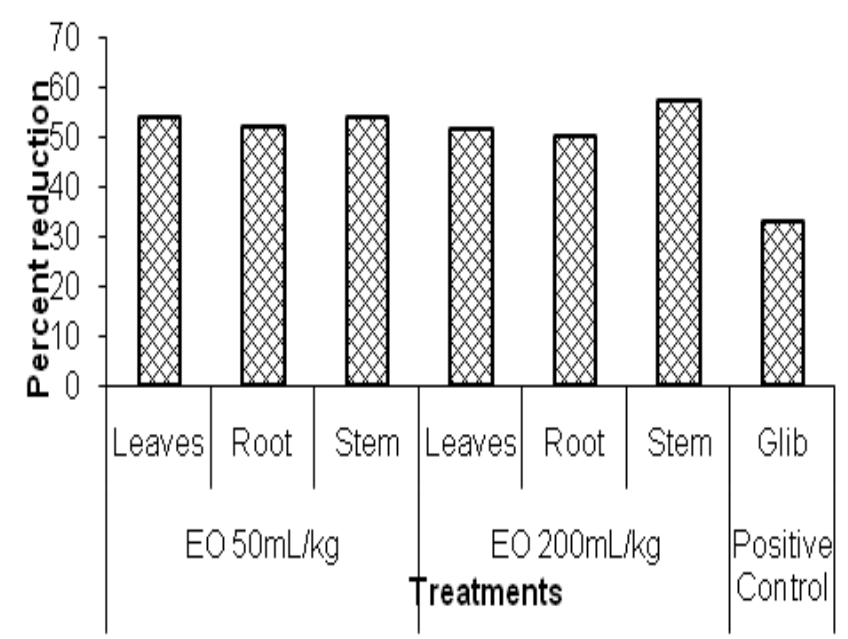

Figure I Percent reduction in Glucose level by different Essential oils as compared with Positive control in rabbits $(n=5)$.

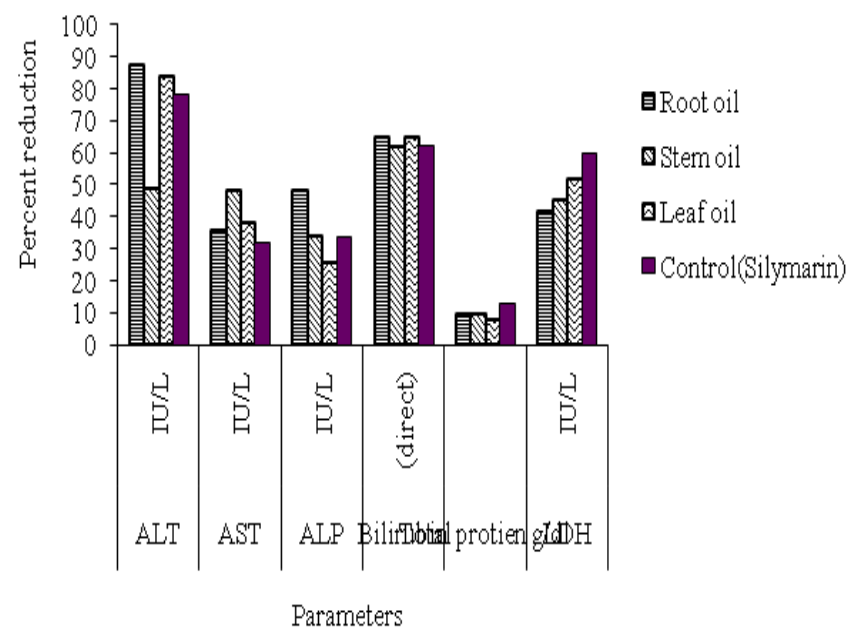

Figure 2 Percent reduction by different Essential oils in different elevated values in different biochemical markers as compared with Positive control in rats $(n=5)$.

\section{Acknowledgements}

None.

\section{Conflict of interest}

The author declares no conflict of interest

\section{References}

1. Gaur RD. Flora of the District Garhwal North west Himalaya. 1st ed. Srinagar (Garhwal) India, Trans Media Publication, Srinagar, India; $1999.811 \mathrm{p}$.

2. Sood VK, Karnik MG, Sagar V, et al. Preliminary Investigation on the Essential Oil of Boenninghausenia Albiflora (hook) Reichb. Indian Forest. 1966;92(5):295-299.

3. Yamaha J, Miki S, Murakami H, et al. Occurrence of dictamnine in Boenninghausenia albiflora avr. Japonica. Yakugaku Zasshi. 1987;107:823827.

4. Recknagel RO, Glende EA Jr, Dolak JA, et al. Mechanisms of carbon tetrachloride toxicity. Pharmacol Ther. 1989;43(1):139-154.

5. Anonymus. Acute oral toxic class method, guideline 423 adopted. In $11^{\text {th }}$ Addendum to the OECD guidelines for the testing of chemicals. Paris: Organization for Economic Co-operation. 1996. p. 1-14.

6. Elsner M, Guldbakke B, Tiedge M, et al. Relative importance of transport and alkylation for pancreatic beta-cell toxicity of streptozotocin. Diabetologia. 2000;43(12):1528-1533.

7. Rajanarayana K, Reddy MS, Chaluvadi MR, et al. Bioflavonoids classification, pharmacological, biochemical effects and therapeutic p potential. Indian J Pharmacol. 2001;33:2-16.

8. Chidambara-Murthy KN, Jayaprakasha GK, Singh RP. Studies on antioxidant activity of pomegranate (Punica granatum) peel extract using in vivo models. J Agric Food Chem. 2002;50(17):4791-4795.

9. Sumitha P, Thirunalasundari T. Hepatoprotective Activity of Aegel marmelos in $\mathrm{CCl}_{4}$ Induced Toxicity-An In-vivo Study. J Phytol. 2011;3(9):5-

10. Verma N, Khosa RL. Hepatoprotective activity of leaves of Zanthoxylum armatum $\mathrm{DC}$ in $\mathrm{CCl}_{4}$ induced hepatotoxicity in rats. Indian J Biochem Biophys. 2010;47(2):124-127.

11. Kangralkar VA, Gavimath CC, Jadhav NA, et al. Potential hypoglycemic effect Of essential oil of Citrus Reticulata in wistar rats. Interntl J Pharma Appl. 2010;1(1):6-9.

12. Kalviani T, Premkumar N, Ramya S, et al. Investigations on hepatoprotective activity of leaf extracts of Aegel marmelos (L.) Corr. (Rutaceae). Ethnobotanical Leaflets. 2009;13:47-50.

13. Rajasekaran C. Kalaivani T, Ramya S, et al. Studies on hepatoprotective activity of ethanolic extracts of fruit pulp of Aegel marmelos (L.). Corr J Pharm Res. 2009;2(9):1419-1423.

14. Pande MS, Dupta SPBN, Pathak A. Hepatoprotective Activity of Murraya koenigii bark. J Herb Med and Toxicol. 2009;3(1):69-71.

15. Subramaniam V, Adenan MI, Ahmad AR, et al. Natural antioxidants: Piper sarmentosum (Kadok) and Morinda elliptica (Mengkudu). Mal J Nutr. 2003;9(1):41-51. 